\title{
KOMUNIKASI INSTRUKTIF GURU DALAM MENINGKATKAN PRESTASI BELAJAR SISWA SMP INSAN NUR MUHAMMAD
}

\section{TEACHER'S INSTRUCTIVE COMMUNICATION IN IMPROVING STUDENT LEARNING ACHIEVEMENT OF INSAN NUR MUHAMMAD JUNIOR HIGH SCHOOL}

\author{
Holid Hidayat $^{1}$, Ike Atikah Ratnamulyani ${ }^{2 *}$, Agustini ${ }^{3}$. \\ No 1 Kotak Pos 35 Bogor 16720 \\ *Korespondensi: ikea.ratnamulyani@gmail.com \\ (Diterima oleh Dewan Redaksi: 01-08-2019) \\ (Dipublikasikan oleh Dewan Redaksi: 01-10-2019)
}

${ }^{123}$ Program Studi Sains Komunikasi, Fakultas Ilmu Sosisal dan Ilmu Politik, Universitas Djuanda Bogor Jl. Tol Ciawi

\begin{abstract}
The implementation of instructive communication techniques to students at SMP Insan Nur Muhammad, is done to improve student learning achievement. Learning achievement can be reached with support and motivation from school and home, good cooperation between the school and home becomes important in motivating students to have achievement. As Marwan who initially had difficulty in carrying out his duties as a BK teacher, giving guidance to students who were not disciplined to motivate student to study, but eventually Marwan succeeded in making students of SMP Insan Nur Muhammad outstanding and SMP Insan Nur Muhammad became one of the best schools in Tenjolaya District by getting several awards in various competitions among schools. The research aims to find out instructive communication in improving students learning achievement. The descriptive qualitative research method explains the phenomena accurately about the facts. Data collection techniques is done by observation, in-depth interviews, books, documentation, reports, and information. The results showed that instructional communication made by teachers with Fear Arousing, threats that given as punishment to students who are late, suspensions, parents' summons, and repeat the same class to discipline and motivate students to become responsible, disciplined and outstanding students. This is also done by Red Hearring, the content of interests to win in a conflict such as direction, explanation, belief, attention and understanding so that students become disciplined, follow the rules and become excellent students. The conclusion is BK teacher succeeded in providing motivation to students in their learning achievement.
\end{abstract}

Keywords: Instructive Communication; Teacher; Learning Achievement; Students; School 


\begin{abstract}
ABSTRAK
Penerapan teknik komunikasi instruktif pada siswa di SMP Insan Nur Muhammad, dilakukan untuk meningkatkan prestasi belajar siswa, prestasi belajar dapat diraih dengan dukungan dan motivasi dari sekolah maupun rumah, kerja sama yang baik antara pihak sekolah dan rumah menjadi hal penting dalam memotivasi siswa untuk meraih prestasi. Seperti Marwan, awalnya kesulitan dalam menjalankan tugasnya sebagai guru BK dan memberikan pengarahan kepada siswa yang tidak disiplin sampai memotivasi belajar siswa. Namun akhirnya marwan berhasil membuat siswa SMP Insan Nur Muhammad menjadi siswa yang berprestasi dan SMP Insan Nur muhammad menjadi salah satu sekolah terbaik di Kecamatan Tenjolaya dengan mendapatkan beberapa penghargaan-penghargaan di berbagai perlombaan antar sekolah. Penelitian bertujuan untuk mengetahui komunikasi instruktif dalam meningkatkan prestasi belajar siswa. Metode penelitian deskriptif kualitatif menjelaskan fenomena secara akurat tentang faktafakta yang ada. Teknik pengumpulan data dari observasi, wawancara mendalam, buku, dokumentasi, laporan, dan informasi. Hasil penelitian menunjukan komunikasi instruktif dilakukan guru dengan Fear arousing yaitu ancaman yang diberikan seperti hukuman kepada siswa yang terlambat, skors, pemanggilan orang tua, dan tidak akan naik kelas. untuk mendisiplinkan dan memotivasi siswa agar menjadi siswa yang bertanggung jawab, disiplin dan berprestasi. Juga dengan Red Hearring yaitu muatan kepentingan untuk meraih kemenangan dalam suatu konflik seperti pengarahan, penjelasan, kepercayaan, perhatian dan pengertian sehingga siswa menjadi disiplin, mengikuti aturan dan menjadi siswa-siswi yang berprestasi. Kesimpulan penelitian ini adalah guru BK berhasil memberikan motivasi kepada siswa dalam prestasi belajarnya.
\end{abstract}

Kata Kunci: Komunikasi Instruktif; Guru; Prestasi Belajar; Siswa; Sekolah

Holid Hidayat, 2019. Komunikasi Instruktif Guru Dalam Meningkatkan Prestasi Belajar Siswa SMP Insan Nur Muhammad. 


\section{PENDAHULUAN}

Guru SMP Insan Nur Muhammad menerapkan komunikasi instruktif dalam proses belajar siswa di sekolah, hal ini dilakukan agar siswa termotivasi dalam meraih prestasi belajar dan mampu beradaptasi dengan lingkungan sekolahnya.

Prestasi belajar adalah penilaian terhadap hasil belajar siswa untuk mengetahui sejauh mana siswa telah mencapai sasaran belajar. Seperti yang dikatakan Marsun dan Martaniah (dalam Sia Tjunjing, 2000), prestasi belajar merupakan hasil kegiatan belajar yaitu sejauh mana siswa menguasai bahan pelajaran yang diajarkan dan diikuti munculnya puas bahwa ia telah melakukan sesuatu dengan baik.

Hasil wawancara dengan Solihat pada tahun 2018, prestasi belajar dapat diraih dengan dukungan dan motivasi dari sekolah maupun rumah. Ada kerja sama yang baik antara pihak sekolah dan orangtua di rumah menjadi hal penting dalam memotivasi siswa untuk meraih prestasi. Selain itu, prestasi belajar dapat diraih dengan baik oleh anak dengan dukungan orang tua dan guru baik di rumah ataupun di sekolah. Kerja sama antara orang tua dan guru menjadi hal penting dalam meningkatkan prestasi belajar siswa. Tidak hanya dukungan guru dan orangtua, anak juga harus mampu menghadapi berbagai kendala yang dihadapi selama mengikuti pembelajaran di sekolah.

Menurut Marwan selaku kesiswaan di SMP Insan Nur Muhammad, banyak siswa-siswi yang mengeluh akan kurangnya perhatian dari orangtua dalam memotivasi belajar anak. Bahkan banyak anak yang tidak terlalu mementingkan prestasi karena orang tua tidak pernah menanyakan atau memperhatikan apa yang menjadi masalah anak di sekolah dan kekurangan anak dalam menyerap setiap mata pelajaran yang diberikan guru di kelas. Seperti halnya menanyakan PR (pekerjaan rumah), ataupun nilai ulangan harian, ulangan semester, dan lain-lain.

Adapun Umiarti sebagai Kepala Sekolah SMP Insan Nur Muhammad mengatakan, orang tua merupakan guru pertama yang memberikan ilmu di rumah kepada anak. Di rumah anak dapat belajar tentang banyak hal yang mendasar. Ilmu yang diperoleh anak di rumah merupakan fondasi bagi hidupnya di masa depan. Maka orang tua harus selalu mengajarkan, menambahkan dan memupuk hal-hal yang baik kepada anak sejak masih kecil supaya menjadi suatu kebiasaan yang baik sampai menjadi dewasa nanti karena anak sangat berharga dimata siapapun khususnya orang tua. Selain mengasuh, merawat dan membesarkan anak, orang tua mempunyai tugas yang tidak kalah penting yaitu memberikan pendidikan yang terbaik bagi putra-putri mereka. Disini peran orang tua dalam hal pendidikan anak sudah seharusnya berada pada urutan pertama. Sehingga yang harus dilakukan para orang tua antara lain memilih sekolah yang tepat untuk anak, membimbing mereka dalam belajar, sebagai fasilitator, dan sebagai pemberi motivasi atau motivator.

Pendapat Daradjat (2000), orang tua adalah pendidik utama dan pertama bagi anak-anak mereka karena dari merekalah anak mula-mula menerima pendidikan maka bentuk pertama dari pendidikan terdapat dalam kehidupan keluarga. Banyak cara yang dapat dilakukan orangtua dalam mendidik anaknya dirumah, seperti memberikan pendidikan yang layak, memberikan motivasi belajar, menjadi fasilitator dan membimbing anaknya dalam segala hal. Adapun cara yang lebih efektif dalam membantu anak meningkatkan prestasi belajarnya, yaitu dengan melakukan strategi instruktif.

Terkait dengan komunikasi
instruktif adalah berupa perintah, ancaman, sanksi dan lain-lain yang bersifat paksaan dimana orang-orang yang dijadikan sasaran (komunikan) 
melakukannya secara terpaksa (Mulyana, 2010).

Berdasarkan latar belakang di atas, maka dirumuskan masalah: 1) Bagaimana komunikasi instruktif yang dilakukan guru dengan siswa? 2) Bagaimana komunikasi instruktif dapat meningkatkan prestasi belajar siswa?

\section{MATERI DAN METODE}

Penelitian menggunakan metode deskriptif kualitatif yang menggambarkan secara akurat tentang fakta-fakta yang ada. Kualitatif, menurut Kriyantono (2008), adalah penelitian yang menjelaskan fenomena secara akurat. Subyek penelitian, pihak dari sekolah SMP Insan Nur Muhammad dengan informan utama, Guru BK (Bimbingan Konseling) SMP Insan Nur Muhammad. Teknik pengumpulan data meliputi data primer dengan observasi dari kegiatan mengamati secara langsung kegiatan belajar mengajar di sekolah SMP Insan Nur Muhammad dan wawancara mendalam untuk memperoleh informasi dari informan. Sedangkan data sekunder diperoleh dari buku, dokumentasi, laporan dan informasi yang dikeluarkan dari sekolah. Teknik analisis data dilakukan dengan triangulasi sumber yaitu membandingkan suatu informasi yang diperoleh dari informan yang berbeda kemudian ditarik suatu kesimpulan yang sesuai dengan fakta yang ada di lapangan. Selanjutnya triangulasi teori yaitu memanfaatkan teori untuk dipadu dengan hasil wawancara dengan informan dan pengamatan secara langsung.

\section{HASIL DAN PEMBAHASAN}

Teknik berbicara efektif, menurut Mulyana (2010), adalah berbicara secara menarik dan jelas sehingga dapat dimengerti dan mencapai tujuan yang diharapkan dalam komunikasi. Sedangkan teknik berbicara dalam berkomunikasi harus menyesuaikan diri antara
Komunikasi Instruktif Guru Dalam Meningkatkan Prestasi Belajar Siswa SMP Insan Nur Muhammad

komunikator dan komunikan kepada pesan (Message) yang dipercakapkan.

Adanya komunikasi yang benar siswa akan mudah untuk menyerap segala sesuatu yang akan diajarkan guru pada saat pembelajaran (Pratama, dkk, 2015).

Menurut Slameto (2010), sekolah merupakan kegiatan yang berat dalam proses belajar banyak dijumpai kesulitan, kadang-kadang anak mengalami lemah semangat.

Sedangkan guru, menurut Imran (2010), adalah jabatan atau profesi yang memerlukan keahlian khusus dalam tugas utamanya seperti mendidik, mengajar, membimbing, mengarahkan, melatih, menilai, dan mengevaluasi siswa pada pendidikan anak usia dini jalur pendidikan formal, pendidikan dasar, dan menengah.

Berdasarkan hasil wawancara dengan Marwan pada tahun 2018, guru kesiswaan di kelas dan sekaligus guru Biro Konseling (BK) bahwa prestasi belajar muncul tidak luput dari perjuangan dan sikap yang diperlihatkan oleh siswa di sekolah. Mereka sangat mudah beradaptasi dengan lingkungannya, mampu menyesuaikan diri dengan lingkungan dan peraturan sekolah yang berlaku di SMP Insan Nur Muhammad. Walaupun tidak sedikit permasalahan yang mereka hadapi tetapi tidak mematahkan semangat mereka untuk berprestasi di sekolah. Keberhasilan siswa tidak luput dari didikan guru dan orangtua sebagai pihak intern dan ekstern dari siswa.

Keberhasilan siswa di sekolah didukung orangtua yang selalu berkomunikasi di rumah seperti untuk mengubah sikap, pendapat, dan perilaku anak untuk dapat bersikap baik. Wawancara dengan Ros sebagai orang tua dari Rohmat siswa kelas VII, dalam menghadapi anaknya dengan cara memberikan kepercayaan seperti memberikan izin setiap ada kegiatan tambahan diluar sekolah. Anak butuh kepercayaan agar anak dapat belajar bertanggung jawab dengan kepercayaan 
yang diberikan orang tuanya. Hal ini sangat efektif dilakukan orang tua mengingat anak butuh kebebasan untuk dapat mengeksplor semua hal dan dapat memberikan ilmu dan wawasan untuk dirinya. Namun tidak luput dari pengawasan dan aturan yang diberikan orang tua, pengawasan ini dilakukan agar dapat mengetahui sejauh mana perkembangan anak baik dirumah maupun di lingkungan sekolah.

Lain halnya dengan Erna, berkomunikasi dengan anaknya dengan cara memberikan motivasi belajar seperti menceritakan orang-orang yang berhasil dalam dunia pendidikan untuk dapat memotivasi dan anak dapat terinspirasi dari cerita yang diberikan. Erna menjelaskan perjalanan pendidikan pamannya yang walaupun memiliki latar belakang keluarga kurang mampu tetapi paman mampu meraih gelar sarjana di Universitas Pakuan Bogor.

Hal ini diperkuat siswa itu sendiri meskipun keberhasilan siswa selain dari dorongan dirinya juga motivasi dari guru dan orang tuanya di rumah. Seperti dikatakan Rohmat (2019) bahwa selain guru di sekolah motivasi terbesar dalam pendidikan adalah orang tuanya, dia merasa bahwa orangtua merupakan faktor utama sehingga bisa mencapai prestasi sejauh ini. Selalu meyakinkan orang tuanya bahwa dia mampu menjadi siswa yang berprestasi dengan cara rajin belajar, menjaga sikap, menjaga pergaulan, mendengarkan semua arahan dari guru dan orang tuanya, tidak pernah memiliki masalah di sekolah dan sebagainya. Namun dibalik prestasi yang diperoleh banyak pula kendala yang dihadapi seperti membagi waktu antara membantu orang tua, menjaga adik dan belajar, diejek teman sekolah, bersaing dengan teman sekelasnya dan lain-lain.

Sefti juga mengatakan hal yang sama, motivasi terbesarnya adalah orang tua, dia ingin membahagiakan orang tuanya dengan prestasi yang diperoleh. Adapun kendala yang dihadapi seperti harus membagi waktu antara belajar dengan membantu orang tua, menjaga adik, dan bersaing dengan teman-teman di kelasnya.

Dalam hal ini Menurut (Dalyono M, 2005) guru sebagai pendorong (Motivator) yang datang dari luar (Ekstrinsik) diri (lingkungan) selain dari dalam diri (Intrinsik) dari siswa di sekolah. Dikatakannya motivasi adalah daya penggerak atau pendorong untuk melakukan suatu pekerjaan yang berasal dari dalam diri (Intrinsik) yaitu dorongan yang datang dari hati sanubarinya karena kesadaran akan pentingnya sesuatu. Sedangkan motivasi yang berasal dari luar (Ekstrinsik) yaitu dorongan yang datang dari luar diri (lingkungan), misalnya dari orang tua, guru, teman-teman, dan anggota masyarakat.

Adapun dalam prestasi atau hasil yang telah dicapai siswa dalam proses pembelajaran. Menurut (Wijaya, 1994), prestasi belajar itu dapat berupa pernyataan dalam bentuk angka dan nilai tingkah laku. Diperkuat Thotndike dan Hasein bahwa hasil belajar akan diketahui bila terjadi perubahan tingkah laku yang akan dinyatakan dalam angka atau nilai. Sedangkan (Nawawi, 1998) mengatakan, prestasi belajar adalah tingkatan keberhasilan siswa dalam mempelajari materi pelajaran di sekolah yang dinyatakan dalam bentuk skor yang diperoleh dari hasil tes dari sejumlah materi tertentu.

Lebih jelasnya (Tulus tu'u, 2004) bahwa prestasi belajar siswa: Pertama, hasil belajar yang dicapai siswa ketika mengikuti dan mengerjakan tugas dan kegiatan pembelajaran di sekolah. Kedua, prestasi belajar siswa tersebut terutama dinilai aspek kognitifnya karena bersangkutan dengan kemampuan siswa dalam pengetahuan atau ingatan, pemahaman, aplikasi, analisis, sintesis dan evaluasi. Ketiga, prestasi siswa dibuktikan dan ditujukan melalui nilai atau angka nilai dari hasil evaluasi yang dilakukan oleh guru terhadap tugas siswa dan ulanganulangan atau ujian yang ditempuhnya. 
Berdasarkan wawancara dengan guru kelas dan selaku guru BK (Bimbingan Konseling), Marwan pada tahun 2019 mengatakan, prestasi belajar siswa merupakan hasil pencapaian yang dilakukan siswa untuk mengetahui dan mengukur kemampuan sejauh mana siswa mampu menguasai materi pembelajaran baik dibidang akademik atau ekstrakulikuler.

Selanjutnya, dalam menjalankan tugasnya sebagai guru BK, mendapatkan berbagai kendala seperti dalam menghadapi siswa nakal, sering terlambat sekolah, tidak mengikuti peraturan sekolah dengan baik, tidak menggunakan atribut sekolah dengan benar, bolos sekolah, tidak mengerjakan tugas yang diberikan guru dan lain-lain.

Marwan sebagai guru di kelas sekaligus guru BK, menerapkan teknik komunikasi instruktif pada siswa, yaitu ancaman yang diberikan seperti memberikan hukuman kepada siswa yang terlambat, memberikan skors, pemanggilan orang tua, dan diancam tidak akan naik kelas. Tujuannya untuk mendisiplinkan dan memotivasi siswa agar menjadi siswa yang bertanggung jawab, disiplin dan berprestasi.

Adapun teknik komunikasi yang dilakukan guru dengan siswa, komunikasi instruktif (Instruktive Communication), yang menurut Yasir (2009), komunikasi instruktif (Instructive Communication) yaitu komunikasi yang dilakukan dengan cara memberi perintah kepada penerima pesan. Biasanya juga dipakai istilah komunikasi instruksional yang sering digunakan dalam bidang pendidikan, untuk mempengaruhi anak atau peserta didik.

Senada dengan pernyataan di atas (Mulyana, 2010) menjelaskan, komunikasi instruktif yaitu komunikasi berupa perintah, ancaman, sanksi dan lain-lain yang bersifat paksaan, sehingga orangorang yang dijadikan sasaran (komunikan) melakukannya secara terpaksa. Biasanya teknik komunikasi seperti ini bersifat Fear
Komunikasi Instruktif Guru Dalam Meningkatkan Prestasi Belajar Siswa SMP Insan Nur Muhammad

Arousing, yang sifatnya menakut-nakuti atau menggambarkan resiko yang buruk, serta tidak luput dari sifat Red-Hearring yang interest atau bermuatan kepentingan untuk meraih kemenangan dalam suatu konflik, perdebatan dengan menepis argumentasi yang lemah kemudian dijadikan untuk penyerang lawan.

Selain memberikan ancaman kata (Marwan, 2019) dalam wawancara, selalu memberikan pengarahan, penjelasan, kepercayaan, perhatian dan pengertian. Pengarahan ada untuk memberikan instruksi kepada siswa sejauh mana mereka harus mengikuti peraturan sekolah, penjelasan diberikan mengingat siswa yang kritis selalu ingin tahu mengapa mereka harus mengikuti aturan sekolah. Hal ini sangat membantu dan mendapatkan hasil yang baik sehingga siswa menjadi disiplin, mengikuti aturan dan menjadi siswa-siswi yang berprestasi.

Lain halnya dengan yang dikatakan (Abdurrahman, 1993), komunikasi instruktif sebagai komunikasi yang bersifat memaksa dengan menggunakan sanksisanksi. Sehingga pesan yang akan disampaikan dalam bentuk komunikasi ini adalah secara agitasi dengan penekanan yang menimbulkan tekanan batin dan ketakutan di antara sesamanya dan pada kalangan publik, mempengaruhi opini, sikap, dan tingkah laku individu, dengan cara tersebut adalah cara yang mudah dan hanya dapat dilakukan di Negara-negara totaliter. Koersif dapat berbentuk perintah, instruksi, dan sebagainya (hal ini biasanya terjadi pada organisasi tipe keledai). Akibat dari kegiatan koersif adalah perubahan sikap pendapat dan tingkah laku dengan perasaan terpaksa karena diancam, yang menimbulkan rasa tidak senang, bahkan rasa benci, mungkin juga dendam.

Suparlan (2018) menyatakan, berkaitan dengan guru yang melakukan teknik instruktif sebagai orang yang tugasnya berupaya mencerdaskan kehidupan bangsa dalam semua aspeknya, 
baik spiritual dan emosional, intelektual, fisikal, maupun aspek lainnya.

Komunikasi instruktif menjadi cara kedua yang sering dilakukan orang tua dalam mendidik anak-anaknya di rumah, komunikasi yang bersifat memaksa ini dapat membangkitkan kedisiplinan dan mendengarkan arahan yang diberikan ataupun guru di sekolah. Karena pesan yang akan disampaikan orang tua dalam bentuk komunikasi ini adalah secara agitasi dengan penekanan yang menimbulkan tekanan batin dan ketakutan, mempengaruhi opini, sikap, dan tingkah laku individu.

Dikatakan Ros sebagai orangtua siswa bahwa ia menerapkan beberapa peraturan di rumahnya karena merasa walaupun diberi kepercayaan anak tetap harus disiplin dan patuh terhadap peraturan-peraturan yang dibuat di rumah. Adapun peraturan yang dibuat di rumah seperti tidak terlambat pulang sekolah, memberi kabar kepada orang tua jika ada kegiatan tambahan di sekolah dan membantu pekerjaan orangtua saat libur sekolah sebelum melakukan aktivitas yang lainnya.

$\begin{array}{cccr} & \text { Begitu Pula dengan Erna sebagai } \\ \text { salah } & \text { satu orangtua siswa yang }\end{array}$ menerapkan aturan-aturan di rumah untuk mendisiplinkan anaknya. Ada pun aturannya seperti tidak bangun siang, merapikan tempat tidur sebelum sekolah, dan membantu pekerjaan rumah tangga di hari libur, serta membatasi waktu bermain.

Hal di atas dipertegas Marwan pada tahun 2018 bahwa komunikasi instruktif juga sangat diperlukan dalam mendidik siswa di sekolah. Marwan melakukan komunikasi Instruktif di sekolah dengan cara memberikan pengarahan agar siswa patuh terhadap peraturan yang ada di sekolah dan memberikan sanksi kepada anak yang melanggar aturan sekolah. Hal tersebut membuat siswa di SMP Insan Nur Muhammad menjadi siswa yang patuh dan disiplin.

Dengan demikian teknik komunikasi instruktif seperti ini bersifat
Fear Arousing, yang dilakukan guru kepada siswa lebih bersifat menakut-nakuti atau menggambarkan resiko yang buruk, serta tidak luput dari sifat Red-Hearring yang interest atau bermuatan kepentingan untuk meraih kemenangan Fear Arousing dalam suatu konflik, perdebatan dengan menepis argumentasi yang lemah kemudian dijadikan untuk penyerang lawan. Selain itu guru melakukan teknik komunikasi bersifat Fear Hearring (Mendengarkan). Seperti yang dikatakan hasil wawancara dengan Rohmat dan Sefti sebagai siswa SMP Nur Muhammad, mengatakan bahwa mereka tidak keberatan dengan peraturan yang diberikan guru di sekolah dalam meningkatkan prestasi belajar siswa.

\section{KESIMPULAN DAN IMPLIKASI}

Simpulan penelitian Komunikasi instruktif guru dengan siswa mampu membangkitkan motivasi dalam meningkatkan prestasi belajar siswa.

Prestasi belajar siswa di SMP Insan Nur Muhammad sangat baik, dan siswa mampu beradaptasi dengan peraturan yang diberikan pihak sekolah.

Guru bimbingan konseling SMP Insan Nur Muhammad Kecamatan Tenjolaya menggunakan Komunikasi Instruktif untuk memberikan pengarahan dan memotivasi siswa agar menjadi siswa yang berprestasi. Komunikasi Instruktif dianggap tepat, hal ini dibuktikan dengan meningkatnya kedisiplinan dan prestasi siswa di sekolah. Pemilihan teknik komunikasi yang tepat memacu keberhasilan meningkatnya prestasi belajar siswa.

\section{DAFTAR PUSTAKA}

Abdurrahman. 1993. Dasar-dasar Public Relation. Bandung: Bina Cipta.

Daradjat, Zakiyah. 2000. Ilmu Pendidikan Islam. Jakarta: Bumi Aksara.

Djamarah, Bahri Syaiful. 2004. Pola Komunikasi Orang Tua dan Anak 
Dalam Keluarga. Jakarta: PT. Reneka Cipta.

Dalyono, M. 2005. Psikologi Pendidikan. Jakarta: PT. Rineka Cipta.

Poerwadarminta. 1998. Kamus Besar Bahasa Indonesia. Jakarta: Pustaka Amani.

Pratama, IA Ratnamulyani, M Fitriah. 2015. Pengaruh Sosial Media Komunikasi Interpersonal Ibu dan Anak Dalam Membangun Motivasi Belajar. Jurnal Komunikatio Prodi Ilmu Komunikasi. Fakultas Ilmu Sosial dan Ilmu Politik. Universitas Djuanda Bogor.

Syaiful. 2004. Pola Komunikasi Orang Tua dan Anak Dalam Keluarga. Jakarta: PT. Reneka Cipta.

Suparlan, Suhartono. 2008. Wawasan Pendidikan Sebuah Pengantar. Pendidikan Yogyakarta: Ar-Ruzz Media.

Yasir. 2009. Pengantar Ilmu Komunikasi. Pekanbaru: Pusat Pengembangan Pendidikan Universitas Riau.
Komunikasi Instruktif Guru Dalam Meningkatkan Prestasi Belajar Siswa SMP Insan Nur Muhammad 